\title{
PIBID e a formação de professores de Química: um relato de experiência
}

\author{
PIBID and the formation of Chemistry teachers: an experience report
}

PIBID y la formación de profesores de Química: un relato de experiencia

Natany Dayani de Souza Assai (natanyassai@id.uff.br)

Universidade Federal Fluminense - UFF.

Sidney Lopes Sanchez Júnior (sid.educacaocp@gmail.com)

Universidade Federal do Paraná - UFPR.

Silvia Fernanda de Souza Lordani (fernandalordani@gmail.com)

Prefeitura Municipal de Santa Amélia - PR.

Patrícia Ferreira Concato de Souza (patricia_concato@hotmail.com)

Prefeitura Municipal de Cornélio Procópio- PR.

Marcia Ines Schabarum Mikuska (mat.mikuska@ufpr.br)

Universidade Federal do Paraná - UFPR.

Resumo: Este trabalho tem como objetivo investigar como as ações do PIBID impactaram na formação profissional dos licenciandos em Química de uma Instituição de Educação Superior pública localizada no Paraná. A coleta de dados ocorreu mediante uma entrevista semiestruturada, a fim de investigar a percepção dos licenciandos acerca das atividades desenvolvidas no PIBID, assim como as contribuições para sua formação. $\mathrm{O}$ movimento analítico demonstrou resultados positivos quanto à contribuição de tal política no desenvolvimento e construção de sua prática docente, contudo, apontam para algumas fragilidades, como a aproximação entre professor orientador, supervisor e licenciandos, o que evidencia a necessidade de estratégias entre os sujeitos constituintes da tríade formativa, para potencializar a formação dos licenciandos, corroborando aos objetivos do programa.

Palavras-chave: PIBID; formação de professores; Química; prática docente.

Abstract: This work aims to investigate how PIBID actions impacted the professional training of undergraduate students in Chemistry at a public Higher Education Institution located in Paraná. Data collection took place through a semi-structured interview, in order to investigate the perception of graduates about the activities developed at PIBID, as well as the contributions to their training. The data revealed that such a policy helps in the development and construction of their teaching practice, however, they point to some weaknesses, such as the approximation between professor, supervisor and undergraduate students, which highlights the need for strategies among the subjects that

Recebido em: 26/04/2021

Aceite em: 01/09/2021 
make up the formative triad, to enhance the training of graduates, corroborating the objectives of the program.

Keywords: PIBID; teacher training; Chemistry; teaching practice.

Resumen: Este trabajo tiene como objetivo investigar cómo las acciones de PIBID impactaron en la formación profesional de estudiantes de pregrado en Química en una Institución de Educación Superior pública ubicada en el Paraná. La recolección de datos se realizó a través de una entrevista semiestructurada, con el fin de investigar la percepción de los egresados sobre las actividades desarrolladas en PIBID, así como los aportes a su formación. Los datos revelaron que dicha política ayuda en el desarrollo y construcción de su práctica docente, sin embargo, señalan algunas debilidades, como la aproximación entre profesor, supervisor y estudiantes de pregrado, lo que resalta la necesidad de estrategias entre las asignaturas que componen la tríada formativa, para potenciar la formación de los egresados, corroborando los objetivos del programa.

Palabras-clave: PIBID; formación del profesorado; Química; práctica docente.

\section{INTRODUÇÃO}

O distanciamento entre a formação inicial de professores e o cotidiano escolar, muitas vezes impossibilita a compreensão das relações humanas que se dão no contexto escolar, assim como dos processos de ensinar, aprender e seus desafios. Reflexões e pesquisas sobre a formação inicial de professores da Educação Básica tem sido palco de muitas discussões, especialmente a formação inicial de professores química, na tentativa de buscar novas orientações para uma formação sólida e adequada, de modo que não se distancie do cotidiano escolar (SILVA; SCHNETZLER, 2011; CALIXTO, 2020; COUTINHO, MIRANDA, 2019; MALDANER, 2006).

Pensando nisso, o Ministério da Educação instituiu o "Programa Institucional de Bolsa de Iniciação à Docência" (PIBID) sendo uma iniciativa do governo federal ao investir no aperfeiçoamento e na valorização da formação de professores para atuarem na Educação Básica, e por meio deste programa, se objetiva impulsionar a formação de professores em todo país.

Desse modo, por meio da Portaria n. 122 de 16 de setembro de 2009 se institui no âmbito da Coordenação de Aperfeiçoamento de Pessoal de Nível Superior (CAPES) o PIBID, para fins de apoiar a iniciação à docência de estudantes de licenciatura plena das instituições federais e estaduais de Educação Superior, na busca de aprimorar a 
formação docente, valorizar o magistério e contribuir para a elevação da qualidade da Educação Básica.

Se tratando de um programa de iniciação à docência, os participantes estudantes de cursos de Licenciaturas são inseridos no cotidiano de escolas da rede pública, “planejam e participam de experiências metodológicas, tecnológicas e práticas docentes de caráter inovador e interdisciplinar, e que buscam a superação de problemas identificados no processo de ensino-aprendizagem" (BRASIL, 2008). A portaria da CAPES n 96 de 18 de julho de 2013, inclui ainda outras atribuições ao PIBID:

(i) incentivar a formação de docentes em nível superior para a educação básica; (ii) contribuir para a valorização do magistério; (iii) elevar a qualidade de formação inicial de professores nos cursos de licenciatura, promovendo a integração entre a educação superior e a educação básica; (iv) inserir os licenciandos no cotidiano de escolas da rede pública de educação, proporcionando-lhes oportunidades de criação e participação em experiências metodológicas, tecnológicas e práticas docentes de caráter inovador e interdisciplinar que busquem a superação de problemas identificados no processo de ensino- aprendizagem; (v) incentivar escolas públicas de educação básica mobilizando seus professores como conformadores dos futuros docentes e tornando-as protagonistas nos processos de formação inicial para o magistério; (vi) contribuir para articulação entre teoria e prática necessárias à formação docente, elevando a qualidade das ações acadêmicas nos cursos de licenciatura; (vii) contribuir para que os estudantes de licenciatura se insiram na cultura escolar do magistério, por meio da apropriação e da reflexão sobre instrumentos, saberes e peculiaridades do trabalho docente.

É possível notar que todos os objetivos atribuídos pela Capes citados no parágrafo anterior culminam em um denominador comum: a formação do caráter profissional docente dos estudantes. De acordo com Araújo (2017) o PIBID proporciona aos futuros professores um maior contato com as escolas da rede básica, além de possibilitar a relação com o saber da docência, por meio das práticas pedagógicas.

Vale destacar que o PIBID acontece a partir de uma parceria entre as instituições de Educação Superior (IES) e escolas públicas que ofertam a Educação Básica. Para implementação, as IES devem elaborar um projeto para submissão junto à CAPES, para viabilizar a concessão de bolsas e orientações por parte dos docentes. Outra questão importante, é o fato de que o PIBID não tem como objetivo substituir as práticas de Estágio, mas ampliar momentos de observação, reflexão, pesquisa e intervenção em realidades do cotidiano escolar.

Recebido em: 26/04/2021

Aceite em: $01 / 09 / 2021$ 
Assim, o presente artigo visa investigar como as ações do PIBID impactam na formação profissional dos licenciandos em Química de uma instituição de Educação Superior (IES) pública localizada no norte do estado do Paraná. Na IES em questão, o projeto PIBID da Licenciatura em Química constitui o único projeto vigente, o qual buscava desenvolver práticas de ensino diversificadas nas escolas-parceiras.

\section{ENCAMINHAMENTOS METODOLÓGICOS}

Os componentes norteadores dessa pesquisa estão situados no contexto da formação inicial de professores, mais especificamente no PIBID de um curso de Licenciatura em Química de uma universidade federal de Ensino Superior. Nesse sentido, realizou-se uma entrevista com dois estudantes. Haguette (1995) afirma que a entrevista é um processo de interação social, no qual o entrevistador tem a finalidade de obter informações do entrevistado, através de um roteiro contendo tópicos em torno de uma problemática central.

Neste contexto, Minayo (1994) ressalta que a entrevista privilegia a obtenção de informações por meio da fala individual, a qual revela condições estruturais, sistemas de valores, normas e símbolos e transmite, através de um porta-voz, representações de determinados grupos.

A coleta de dados ocorreu por meio de uma entrevista classificada como semiestruturada, pois, proporciona ao entrevistado a possibilidade de discorrer sobre suas experiências, partindo do foco principal proposto pelo pesquisador e concomitantemente, permite respostas livres e espontâneas do informante, valoriza a atuação do entrevistador. As questões-base da entrevista solicitavam aos estudantes a necessidade de discorrer sobre toda sua atuação dentro do programa, desde expectativas iniciais, atividades realizadas, assim como reflexões sobre as mesmas e, principalmente, o impacto dessas ações no seu processo de formação docente. O Quadro 1 apresenta as questões propostas para a entrevista.

Quadro 1 - Entrevista realizadas com os estudantes

1. Há quanto tempo você participa do PIBID?

2. Na sua opinião, qual a função do PIBID?

3. Quais eram suas expectativas quando você se inscreveu para ser bolsista do PIBID? Ou seja, o que você esperava do projeto? Comente se o projeto está

Recebido em: 26/04/2021

Aceite em: $01 / 09 / 2021$ 
conseguindo contemplar suas expectativas iniciais e por quê?

4. O que tem acontecido no projeto que, em sua opinião, mais tem contribuído na sua formação como futuro professor (a) de Química?

5. O que você mais gosta no PIBID?

6. Cite pontos positivos e negativos acerca da sua participação no PIBID.

7. Relate quais as atividades você já realizou no PIBID.

8. Qual atividade você mais gostou de realizar no PIBID? Por quê?

9. Você considera que o PIBID contribuiu na sua formação acadêmica? Por quê?

10. Os professores supervisores na escola contribuem na sua formação dentro do PIBID? Se sim, como?

11. Os professores orientadores na escola contribuem na sua formação dentro do PIBID? Se sim, como?

Fonte: Autores, 2020

Com intuito de preservar a identidade dos dois estudantes entrevistados e após assinarem o Termo de Consentimento Livre e Esclarecido, seus nomes foram codificados por A1 e A2, respectivamente. Os pressupostos metodológicos adotados para a análise das entrevistas estiveram pautados nos pressupostos da Análise Textual Discursiva (MORAES; GALIAZZI, 2011). Na próxima seção apresentamos os relatos de A1 e A2, acerca de sua participação no programa.

\section{UM BREVE RELATO}

O estudante A1 participou do programa por 18 meses, enquanto o estudante A2 esteve no programa por 24 meses. Com isso, é possível afirmar que os dois entrevistados possuem uma trajetória a ser considerada e que agrega valor à pesquisa.

Quando perguntados sobre a função do PIBID, os dois estudantes falam sobre a importância da inserção no futuro ambiente de trabalho.

"Na minha opinião inserir o aluno de licenciatura da realidade escolar para ele ver se consegue se adaptar a ideia de ser professor." (A1)

"Contribuir para a formação de docentes, acredito que essa vivência no ambiente escolar, permite que nós bolsistas criemos um perfil profissional, levando em conta tudo o que aprendemos e presenciamos, com professores e $\operatorname{alunos}(\ldots)^{\prime \prime} .(A 2)$

Recebido em: 26/04/2021

Aceite em: $01 / 09 / 2021$ 
As respostas dos estudantes reiteram a competência (vii) da portaria da CAPES e evidencia que este contato com a escola é primordial para esses licenciandos. O estudante A2 ainda completa:

“(...) contribui para que possamos criar meios, estratégias para tentar melhorar o ensino, sem fugir do contexto que estamos inseridos.” (A2)

Analisando esse aspecto, Nóvoa (1992) aponta que a formação inicial é um lugar de reflexão sobre as práticas, o que permite vislumbrar uma perspectiva dos professores como profissionais produtores de saber e de saber fazer. Quando inserimos um estudante no ambiente escolar, as suas observações e vivência de situações cotidianas, lhes permitem julgar, pensar, propor novas ações e refletir sobre as mesmas.

Sobre as expectativas quando se inscreveram para o PIBID e se o mesmo está conseguindo contemplar as expectativas iniciais, os discentes demonstram amadurecimento tanto em superação de paradigmas anteriores, como no caso de A1, como de necessidades formativas ausentes dentro do programa (A2).

"A minha expectativa era dar aula, mas vi que o objetivo do PIBID não era esse. Hoje trabalhamos com instrumentos diferenciais para o ensino de química para quebrar a rotina do ensino tradicional" (A1).

"Minha maior expectativa era tentar fazer a diferença na vida de muitos alunos de maneira positiva, conseguir mostrar que a Química apesar de extensa, e por vezes complexa é linda e aplicável; buscar meios alternativos de trabalhar os conceitos químicos. Em partes sim, (...) pois já realizei diversas atividades utilizando ferramentas alternativas, como experimentação e jogos didáticos, contudo, não consegui verificar se de fato, isso foi significativo para a vida dos alunos, para a evolução do conhecimento deles" (A2).

É comum que os estudantes confundam as iniciativas do PIBID com o estágio supervisionado das licenciaturas, sendo necessário explicitar que o estágio compreende atividades como a de observação. Nessa etapa o estagiário observa a prática pedagógica dos professores já formados, para posteriormente conduzir atividade de regências em sala. Nesse viés, o PIBID objetiva preparar o educando para o trabalho produtivo e aprendizado de competências próprias da atividade profissional, associando teoria e prática. Além de ser um excelente instrumento de integração entre universidade, escola e comunidade (SANTOS FILHO, 2010).

Recebido em: 26/04/2021

Aceite em: $01 / 09 / 2021$ 
Ambos visam a formação docente, porém cada um tem um caráter específico, devendo ser considerados complementares e não um substituto ao outro. O estágio supervisionado tem sua raiz no projeto político pedagógico, sendo necessário e obrigatório a todos os licenciandos, enquanto o PIBID é um programa financiado pelo governo federal. É uma formação opcional que possui editais de seleção para a escolha de seus participantes, que podem concorrer a uma quantidade determinada de bolsas. Este programa é considerado valorizador e incentivador à docência. A2 retrata uma lacuna existente entre suas ações e atividades propostas versus as atitudes dos alunos, quando relata a ausência de um feedback se as atividades propostas estão contribuindo efetivamente para a aprendizagem dos alunos ou não.

\begin{abstract}
"Nunca tive um retorno confiável a respeito da minha função. Não ouvi dos meus alunos, o quanto meu trabalho contribui ou não para eles no ensino de Química. Então concluo, que sim o projeto atendeu minhas expectativas, mas não possibilitou uma avaliação diagnóstica a respeito do conhecimento dos alunos." (A2)
\end{abstract}

A2 necessita de um feedback para estabelecer reflexões sobre sua ação. É preciso lembrar que esses estudantes ainda não possuem uma extensa experiência, muitas vezes não tendo parâmetros aos quais se basear. Nesse caso, apesar das discussões e considerações dos professores (supervisor e orientador), A2 reitera a importância de haver um feedback dos alunos da escola.

$\mathrm{O}$ fato apontado por $\mathrm{A} 2$, pode ser justificado devido aos pibidianos em determinadas situações irem à escola apenas no momento da aplicação das atividades estabelecidas pelos supervisores e não participarem do processo como um todo, ou seja, a realização do diagnóstico antes da realização das atividades e principalmente, posterior a atividade. Isso culmina na ausência de respostas diretas por parte dos alunos.

Para Contreras (1987), o ensino ocorre num ambiente complexo e incerto que tem que ser interpretado na sua singularidade. É nesse contexto que ocorre uma constante tomada de decisões frente às situações novas e conflitantes, que só pode ser garantida a partir de uma reflexão fundamentada; reflexão essa que permite ao professor modificar a sua prática, dentro de um processo intimamente ligado à dinâmica da aula, a qual por sua vez, também sofrerá alterações resultantes do próprio processo reflexivo.

Recebido em: 26/04/2021

Aceite em: $01 / 09 / 2021$ 
Pimenta (2012) defende que a reflexão sobre a aprendizagem do que e do como ensinar, a reflexão sobre a prática ou as práticas vivenciadas são componentes essenciais e necessários à formação inicial do professor. Contudo, se pensarmos sob uma ótica diferente, vemos que a consciência que o estudante A2 possui sobre a necessidade de retorno sobre as atividades realizadas dentro de sala de aula no PIBID, já indica uma certa reflexão sobre sua prática; sutil, inicial, mas presente.

De todos os fatores possíveis de influir no processo de transformação da prática do professor, talvez seja o próprio professor o fator essencial para que esse processo se inicie. A análise crítica do pensamento docente do senso comum, acerca de suas próprias ideias sobre o quê, por quê, para quem e como ensinar ciências, pode passar a ser uma condição inicial para promover a mudança no modelo didático do professor (LORENCINI JR, 2009). A presença do incômodo, da inquietação, gera o estado de mudança.

Mas dada a existência dessa lacuna, como esta pode ser superada? Apontamos nesse caso, a necessidade de um ajuste, um diálogo entre supervisor da escola, professor orientador da universidade e pibidianos para que ocorra uma interação mais efetiva entre as partes. Os estudantes devem participar de todo o processo educativo dentro da escola e que os professores supervisores os incluam os licenciandos nos planejamentos, e estes professores supervisores também sejam incluídos dentro da universidade, de forma que o trabalho flua melhor.

Assim, alunos e professores são levados a refletir suas práticas e experiências vividas, também diferenciadas. Existe, provavelmente, uma atividade reflexiva espontânea e ela não se produz de maneira igual em cada um. Ocorrerá não nos mesmos momentos e não sobre as mesmas questões e, sobretudo, uns estarão mais inclinados que outros a esse tipo de atividade intelectual. É por isso que o papel do professor é o de instaurar momentos e situações específicas para a reflexão. Segundo Astolfi (1991), a atividade reflexiva deve ser provocada e promovida pelo que os autores chamam de "situações desencadeantes".

Os estudantes participando do processo educativo completo e orientados pelos seus professores de maneira direcionada, vão conseguir efetuar uma reflexão e investigação mais aprofundada, reelaborar práticas e potencializar as atividades, que vai

Recebido em: 26/04/2021

Aceite em: $01 / 09 / 2021$ 
influenciar positivamente em suas novas ações dentro de sala de aula, produzido atividades mais significativas do ponto de vista do aprendizado para os alunos, o que gera uma satisfação também para os supervisores. Esses estudantes vão ser capazes de expandir suas capacidades e competências.

A distância entre os dois licenciandos com os professores formadores (tanto o supervisor quanto o orientador) pode ser evidenciada pelas respostas dos estudantes, como apresentados nos trechos que seguem

\footnotetext{
"Os professores orientadores contribuem pouco, pois não temos uma grande vivência como com a professora supervisora da escola. Apenas nos encontramos para relatar o que está acontecendo no colégio ou para montar algum trabalho para publicação" (A1).

"Aprendo com a professora supervisora da escola como eu devo me comportar diante certas circunstâncias, o que fazer e o que não fazer em situações de conflito" (A2).
}

Zanon (2003) incorpora um modelo de tríade formativa, ao estabelecer a importância das interações entre professor formador - Universidade -, professor supervisor - Educação Básica - e o licenciando, no que se refere ao compartilhamento de saberes como componente formativo

Os estudantes enxergam os professores supervisores como referenciais de padrões de comportamento e atitudes de sala de aula e os professores orientadores apenas como fiscais e sem envolvimento efetivo, todos com lugares estabelecidos. É necessário que haja uma interação, uma triangulação, reuniões, discussões entre todos os eixos envolvidos para que resulte em uma reflexão de todas as partes. Surgem os seguintes questionamentos: Os professores supervisores não podem ser também aqueles que publicam? Os professores orientadores não são justamente aqueles que surgem como intermediários dessa relação e não os alunos?

Segundo Barros et al (2013, p. 2) o projeto busca articular práticas inovadoras no âmbito da formação docente, visando consolidar ações em parceria entre Universidade e escola pública, haja vista terem em comum, ou seja, a disseminação do conhecimento científico e a formação do indivíduo, humanizando- o e dando-lhe subsídios para tornar-se um cidadão crítico-reflexivo. Essa parceria a que Barros se

Recebido em: 26/04/2021

Aceite em: $01 / 09 / 2021$ 
refere não pode acontecer apenas no papel, precisa ser mediada e trabalhada no cotidiano para que de fato, sejam criados cidadãos reflexivos.

Podemos inferir essa deficiência a um fato relatado pelo estudante A1 quando perguntado sobre o que ele não gosta no PIBID.

"Eu sinto falta de professores orientadores na área de ensino. Nossos professores orientadores passam uma base boa, mas sinto falta de docentes que deem ideias e ajudem a escrever trabalhos para serem publicados" (Al).

O estudante A1 relata a dificuldade em escrever trabalhos, serem permeados por mais ideias e também, construir uma relação mais produtiva e reflexiva com as escolas, pelo fato dos dois orientadores do PIBID atualmente, serem da área "dura" da Química (Inorgânica e Físico-Química), e o Ensino de Química não serem sua área dominante e não possuírem experiência na mesma.

Ocorre a necessidade de uma parceria caracterizada pela cooperação. Os formadores devem dimensionar, na interação com os professores, teorias e estratégias educacionais de forma diretamente relacionada com o contexto concreto das escolas e com as situações problemáticas concretas que os professores enfrentam no cotidiano de sua atividade docente.

Quando perguntado aos estudantes se o PIBID tem contribuído para sua formação acadêmica, os dois entrevistados afirmaram positivamente que:

\footnotetext{
"Sim, pois consegui vivenciar a realidade de um colégio estadual e conhecer diversos instrumentos de ensino" (A1).

"Com certeza, pois é através da vivência escolar que pude refletir a minha própria prática, e como poderia melhorar minha metodologia de aula. É na prática que se aprende a como se comportar como futuro profissional docente" (A2).
}

Novamente, podemos perceber que os estudantes retomam a importância da vivência do espaço escolar, é nessa prática que eles vão utilizar o conhecimento teórico historicamente adquirido, e que a partir dela que vão estabelecer reflexões para modificar sua prática.

Recebido em: 26/04/2021

Aceite em: $01 / 09 / 2021$ 
Os saberes da experiência são também aqueles que os professores produzem no seu cotidiano docente, num processo permanente de reflexão sobre a prática. Dessa forma, as vivências em sala de aula podem ser um divisor de águas na formação de um professor, contribuindo para reafirmar suas escolhas, rever suas ações a partir da análise de sua prática ou de outro profissional, através da observação, levando em conta os resultados dela para o desenvolvimento do educando (RODRIGUES, FERNANDES, FONTINELES, 2013)

Segundo Pimenta (1997) mobilizar os saberes da experiência é o primeiro passo de um curso que propõe mediar o processo de construção de identidade dos futuros professores. Desta forma, A2 reforça as ideias de Pimenta ao dizer que a prática permeia sua construção profissional. Para finalizar, Pimenta ainda define o que é uma identidade profissional.

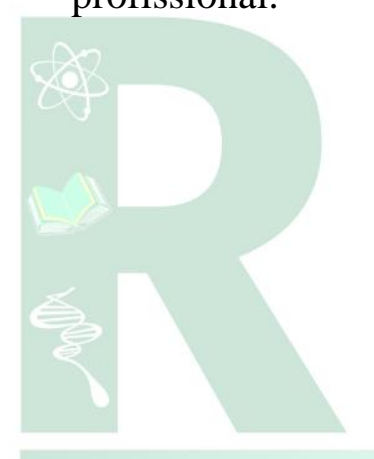

Uma identidade profissional constrói-se com base na significação social da profissão; na revisão constante dos significados sociais da profissão; na revisão das tradições. [...] Constrói-se também pelo significado que cada professor, como autor e ator, confere à atividade docente no seu cotidiano em base em seus valores, seu modo de situar-se no mundo, suas histórias de vida, suas representações, seus saberes, suas angústias e seus anseios (PIMENTA, 1997, p. 42).

O PIBID se caracteriza por construir essa significação da profissão, a partir do contato com o futuro ambiente de trabalho o estudante compreende os significados sociais da profissão, suas tradições, assim como por meio de sua experiência e confronto com as teorias, reflete sobre sua prática, seu contexto, seu público, e se torna capaz de transformar essa realidade em prol da aprendizagem dos alunos, utilizando suas características e valores individuais para um melhor desempenho coletivo.
}

\section{TECENDO CONSIDERAÇÕES}

Diante do exposto, o relato das experiências dos licenciandos integrantes do PIBID, é inegável a contribuição do programa para a formação inicial docente. Além disso, os reflexos dessa boa formação inicial se darão na prática desses futuros professores e também, em suas formações continuadas.

Recebido em: 26/04/2021

Aceite em: $01 / 09 / 2021$ 
Os estudantes se mostraram maduros, compreendendo a função do programa, as contribuições, fazendo algumas reflexões pertinentes e com entendimento das deficiências do programa na instituição a qual são vinculados.

A partir desses relatos foi possível também chegar à conclusão de que apesar de um dos objetivos centrais dos programas ser a articulação entre universidade e escola, o funcionamento e interações entre a tríade formativa encontra-se falha, necessitando de ajustes para possibilitar um melhor desempenho e maior profundidade de reflexões entre todos os eixos envolvidos, principalmente no que tange os futuros profissionais em formação. Nesse movimento de formação de professores estamos aprendendo coletivamente a construirmos essa parceria entre a escola da Educação Básica e a Universidade, ou seja, é um processo de formação e em alguns casos o tempo de apenas 18 ou 24 meses nem sempre proporciona esse sentimento de pertencimento pois é para além do espaço-tempo cronológico do projeto. Nesse sentido, inferimos que o programa está, de fato, semeando novas oportunidades para a formação inicial de professores.

\section{REFERÊNCIAS}

ARAÚJO, R. N. A formação da identidade docente no contexto do PIBID: um estudo à luz das relações com o saber. Tese de Doutorado (Programa de Pós-Graduação em Ensino de Ciências e Educação Matemática do Centro de Ciências Exatas) Universidade Estadual de Londrina, 2017.

ASTOLFI, J-P.; PETERFALVI, B.; VÉRIN, A. Compétences methodologiques en sciences espérimentales. Paris: INRP, 1991. 175p.

BARROS, et al. PIBID X ESCOLA PÚBLICA: uma parceria na melhoria da qualidade do ensino e da aprendizagem das séries iniciais do ensino fundamental. Anais Fiped (2013). v.1, n.2. Vitória da Conquista: Realize editora, 2013.

BRASIL, Ministério da Educação. Fundação CAPES. PIBID- Programa Institucional de Bolsa de Iniciação à Docência. 2008.

CALIXTO, V. S. O debate de perspectivas teóricas da experimentação pedagógica como uma estratégia na formação de professores de Química: com a palavra os licenciandos. Revista Insignare Scientia. v. 3, n. 1, jan./abr./ 2020.

CONTRERAS, J. De estudiante a profesor: Socialización y aprendizaje em las prácticas de enseñanza. Revista de Educación, nº 282, 1987.

Recebido em: 26/04/2021

Aceite em: $01 / 09 / 2021$ 
COUTINHO, C.; MIRANDA, A. C. G. Formação inicial de professores de Ciências da Natureza: relatos de uma prática docente diferenciada. Revista Insignare Scientia. v.2 n. 2, 2019.

HAGUETTE, T. M. F. Metodologias qualitativas na sociologia. 4. Ed. Petrópolis: Vozes, 1995.

LORENCINI JR, A. As Demandas Formativas do Professor de Ciências. In: CAINELLI, Marlene Rosa; SILVA, Ileizi Fiorelli (Organizadoras). O Estágio na Licenciatura: a formação de professores e a experiência interdisciplinar na Universidade Estadual de Londrina. Londrina: UEL, p.21-42. 2009.

MALDANER, O.A. A formação inicial e continuada de professores de química: professores/pesquisadores. 3. ed. Ijuí: Ed. Unijuí, 2006.

MINAYO, M. C. de S. O desafio do conhecimento: pesquisa qualitativa em saúde. 3. ed. São Paulo: Hucitec/Abrasco, 1994.

MORAES, R.; GALIAZZI, M. do C. Análise textual discursiva. 2 ed. Ijuí: Ed. Ijuí, 2011.

NÓVOA, A. Formação de professores e profissão docente. In: (Coord). Os professores e sua formação. Lisboa: Dom Quixote, 1992. P.15-34.

Portaria CAPES nº 096, de 18 de julho de 2015. Disponível em: http://www.capes.gov.br/educacao-basica/capespibid. Acesso em: 08 abril 2015.

RODRIGUES, M. A. S.; FERREIRA, S. J. L.; FONTINELES, I. C. L. O PIBID na formação de professores: contribuições e ações do PIBID para formação inicial dos bolsistas. Anais Fiped (2013). v.1, n.2. Vitória da Conquista: Realize editora, 2013.

SANTOS FILHO, A. P. O Estágio Supervisionado e sua importância na formação docente. Revista P@rtes. 2010.

SILVA, R.M.G.; SCHNETZLER, R.P. Estágios curriculares supervisionados de ensino: partilhando experiências formativas. EntreVer, Florianópolis, v. 01, p. 116-136, 2011.

ZANON, L. B. Interações de licenciandos, formadores e professores na elaboração conceitual de prática docente: módulos triádicos na licenciatura de Química. 2003. 282 f. Tese (Doutorado em Educação) - Universidade Metodista de Piracicaba, Piracicaba, 2003.

Recebido em: 26/04/2021

Aceite em: $01 / 09 / 2021$ 